\title{
Hypertension Current Concepts and Therapeutics (HCCT)
}

\section{Mini Review}

\section{Hypertension and its effects on brain functioning and cognition}

\author{
Robert Perna* \\ TIRR Challenge Program, Houston, USA
}

\section{Introduction}

Hypertension is significantly associated with vascular disease and organ damage. However, because blood pressure is so dynamic and rarely causes acute symptoms even when elevated, it appears that the risks posed by hypertension are often underdiagnosed and undertreated. For example in a recent large study only $23 \%$ of the individuals (children) who met formal diagnostic criteria for hypertension were diagnosed during their physician visit [1]. Over time hypertension causes insidious vascular damage to many organs including the brain. It is linked to cerebral vascular dysfunction and significant risk for stroke.

The empirical research on hypertension is complex and presents mixed and what could be conceived as conflicting finding. It appears that when considering the potential damage secondary to hypertension there are many mediating and associated variables. Many factors moderate the effects of hypertension and these include degree of elevation, duration, current vascular health, and medical comorbidities that may synergistically accelerate the pressure related damage (such as metabolic syndrome, atherosclerosis, and other vascular disorders) and many other individual factors including family history.

\section{Hypertension and the Brain}

Hypertension accelerates arteriosclerotic changes in the brain contributing to atheroma formation in large diameter blood vessels and arteriosclerosis and dysfunction of small vessels of the cerebral vasculature [2]. These vascular changes incorporate medial thickening and intimal proliferation, result in a reduction of luminal diameter, increased resistance to flow and decline in perfusion [3]. Such hypoperfusion can produce discrete regions of cerebral infarction and diffuse ischemic changes in the periventricular and deep white matter (leukoaraisosis) that has been associated with vascular cognitive impairment.

Empirical research suggests that hypertension often results in diminished brain blood flow and metabolism $[4,5]$. These issues are believed to affect neuronal metabolism, neurochemical transmission and thus diminished brain function. It is also thought to accelerate white matter changes and accelerate atrophy [6]. One might ask why such a dangerous process is rarely discussed outside of acute malignant hypertension.

Changes in blood pressure are associated with changes in brain perfusion and metabolism. The capacity of the neurovascular territories to respond to variation in blood pressure is referred to as dynamic autoregulation and/or brain vascular reserve. Hypertension and the resulting endothelial dysfunction decreases the brains ability for dynamic cerebral autoregulation [7] and perhaps neurovascular coupling (the upregulation in blood flow to match cognitive/cerebral demands). This diminished capacity may contribute to small vessel disease and possibly the diminished clearance of amyloid $\beta$ A4 protein from the brain. The combination of advanced age with hypertension and other risk factors provides a background for multi-faceted interactions in pathophysiological pathways that lead to cognitive decline and dementia [8-11].

\section{Hypertension and Cognition}

Though much of the research on hypertension suggests it causes cognitive dysfunction, some of the research presents mixed finding and even suggests a $U$ shaped relationship between blood pressure and cognitive functioning. Essentially research suggests that both low blood pressure and moderate to severely high blood pressure are associated with suboptimal cognitive functioning. Blood pressure needs to be sufficiently high to maintain cerebral perfusion pressure necessary to adequately perfuse the brain.

The majority of longitudinal studies have demonstrated that prolonged elevated blood pressure to be associated with accelerated cognitive decline [12-14]. Research suggests that people with hypertension perform more poorly than normotensive individuals on measures including learning and memory, attention, visuospatial skills, psychomotor abilities, and executive functioning [5]. Several lines of evidence suggest one of the benefits of lowering blood pressure can significantly reduce the risk of dementia and cognitive decline in older age groups. Treatment for blood pressure (as compared to placebo) has been shown to reduced the amount of decline in mini-mental state examination scores and significantly lower the incidence of dementia $[15,16]$.

\section{Conclusions}

Blood pressure has complex relationships with cognitive functioning. However, the empirical research is reasonably clear that poorly controlled hypertension will eventually significantly increase the risk of cognitive dysfunction and perhaps vascular and possibly other types of dementia. Based on this review it may be important to provide appropriate patient education regarding likely risks associated with hypertension.. Without such education and the asymptomatic

Correspondence to: Robert Perna, TIRR Challenge Program, Houston, USA, E-mail: dr.perna@juno.com

Received: December 02, 2016; Accepted: December 28, 2016; Published: January 03, 2017 
nature of hypertension, many individual may not choose to seek help for this issue.

\section{References}

1. Kaelber DC, Liu W, Ross M, Localio RA, Leon JB, et al (2016) Diagnosis and Medication Treatment of Pediatric Hypertension: A Retrospective Cohort Study for the Comparative Effectiveness Research Through Collaborative Electronic Reporting (CER2) Consortium. Pediatrics 138: 2016-2195

2. Spence JD (1996) Cerebral consequences of hypertension: where do they lead? $J$ Hypertens Suppl 14: S139-145. [Crossref]

3. Skoog I (1998) A review on blood pressure and ischaemic white matter lesions. Dement Geriatr Cogn Disord 9 Suppl 1: 13-19. [Crossref]

4. Jennings JR, Muldoon MF, Ryan CM, Mintun MA, Meltzer CC, et al. (1998) Cerebra blood flow in hypertensive patients: An initial report of reduced and compensatory blood flow responses during performance of two cognitive tasks. Hypertension 31: 1216-1222. [Crossref]

5. Waldstein SR, Katzel LI (2001) Hypertension and cognitive function. In S.R. Waldstein \& M.F. Elias (Eds.), Neuropsychology of cardiovascular disease. Mahwah, NJ: Erlbaum 15-36

6. Schmidt R, Fazekas F, Offenbacher H, Dusek T, Zach E, et al. (1993) Neuropsychologic correlates of MRI white matter hyperintensities: A study of 150 normal volunteers. Neurology 43: 2490-2494. [Crossref]

7. Immink RV, van den Born BJ, van Montfrans GA, Koopmans RP, Karemaker JM, et al. (2004) Impaired cerebral autoregulation in patients with malignant hypertension. Circulation 110: 2241-2245 [Crossref]
8. Carnevale D, Lembo CD (2012) Hypertension and cerebrovascular dysfunction: Acute and chronic brain pathological alterations. High Blood Pressure \& Cardiovascular Prevention 17: 191-200.

9. Nagai M, Hoshide S, Kario K (2010) Hypertension and dementia. American $J$ Hypertension 23(2): 116-24.

10. Staessen JA, Richart T, Birkenhäger WH (2007) Less atherosclerosis and lower blood pressure for a meaningful life perspective with more brain. Hypertension 49: 389-400. [Crossref]

11. Swan GE, DeCarli C, Miller BL, Reed T, Wolf PA, et al. (1998) Association of midlife blood pressure to late-life cognitive decline and brain morphology. Neurology 51: 986993. [Crossref]

12. Launer LJ, Masaki K, Petrovitch H, Foley D, Havlik RJ (1995) The association between midlife blood pressure levels and late-life cognitive function. The HonoluluAsia Aging Study. JAMA 274: 1846-1851. [Crossref]

13. Elias MF, Wolf PA, D'Agostino RB, Cobb J, White LR (1993) Untreated blood pressure level is inversely related to cognitive functioning: the Framingham Study. $A m$ J Epidemiol 138: 353-364. [Crossref]

14. Kilander L, Nyman H, Boberg M, Hansson L, Lithell H (1998) Hypertension is related to cognitive impairment: a 20-year follow-up of 999 men. Hypertension 31: 780-786. [Crossref]

15. Birkenhäger WH, Forette F, Seux ML, Wang JG, Staessen JA (2001) Blood pressure, cognitive functions, and prevention of dementias in older patients with hypertension. Arch Intern Med 161: 152-156. [Crossref]

16. Duron E, Hanon O (2008) Hypertension, cognitive decline and dementia. Arch Cardiovasc Dis 101: 181-189. [Crossref]

Copyright: (C2016 Perna R. This is an open-access article distributed under the terms of the Creative Commons Attribution License, which permits unrestricted use, distribution, and reproduction in any medium, provided the original author and source are credited. 